\title{
PERMAINAN “KIMIA KOTAK KATIK" SEBAGAI MEDIA PEMBELAJARAN PADA MATERI SISTEM PERIODIK UNSUR
}

\author{
Rusly Hidayah ${ }^{1}$, Suprianto ${ }^{1}$, dan Alis Rahmawati ${ }^{1}$ \\ ${ }^{1}$ Jurusan Kimia, Fakultas Matematika dan Ilmu Pengetahuan Alam, Universitas \\ Negeri Surabaya, Kampus Ketintang, Surabaya, 60231, Indonesia \\ E-mail: ruslyhidayah@unesa.ac.id
}

\begin{abstract}
ABSTRAK
Penelitian yang dilakukan bertujuan untuk mendeskripsikan tingkat kelayakan permainan "kimia kotak katik" ditinjau dari isi, dan kontruksi serta untuk mengetahui peningkatan hasil belajar siswa pada materi Sistem Periodik Unsur. Sasaran penelitian ini adalah 12 orang siswa SMA Muhammadiyah 1 Gresik. Rancangan penelitian menggunakan desain One Group Pretest-Postest. Hasil analisis data menunjukan bahwa permainan ini layak digunakan sebagai media pembelajaran dengan presentase kelayakan sebesar 83,33\%. Ketuntasan hasil belajar siswa mencapai $75 \%$. Berdasarkan hasil uji coba, permainan kimia kotak katik layak untuk diterapkan untuk pembelajaran kimia
\end{abstract}

Kata kunci: kimia kotak katik, sistem periodik unsur

\section{ABSTRACT}

This research aimed to describe the feasibility game "kimia kotak katik" in terms of contents, and construction as well as to determine the improvement of student learning outcomes in Periodic Table subject. The targets of this research is 12 students of SMA Muhammadiyah 1 Gresik. The study design used design one group pretest-posttest. Results of data analysation showed that the game is suitable for use as a medium of learning with eligibility percentage of $83.33 \%$. Mastery learning outcome reaching $75 \%$. Based on trial results, Kimia Kotak katik game is eligible to apply to study in chemistry

Keyword: kimia kotak katik, material element of periodic system

DOI: http://dx.doi.org/10.15575/jta.v2i1.1362

\section{PENDAHULUAN}

Pengembangan kurikulum 2013 menuntut agar pola pembelajaran berpusat pada guru berubah menjadi pembelajaran yang berpusat pada siswa (Permendikbud No. 69, 2013). Kurikulum 2013 mengutamakan penggalian informasi yang berpusat kepada peserta didik sehingga siswa dituntut untuk berperan aktif dalam kegiatan belajar mengajar di dalam kelas dimana guru hanya sebagai pembimbing peserta didik dalam menemukan dan menggali informasi.
Perbedaan karakter siswa mengharuskan guru untuk berinovasi dalam mengajar, sehingga materi yang disampaikan dapat diterima seutuhnya. Pola pembelajaran satu arah (interaksi guru-peserta didik) menjadi pembelajaran interaktif (interaktif gurupeserta didik-masyarakat-lingkungan alam, sumber/ media lainnya) (BNSP, 2013) dengan demikian diperlukan media yang sesuai dengan kurikulum selama proses belajar mengajar. 
Pelajaran kimia merupakan salah satu cabang ilmu alam yang sering kita jumpai di kehidupan sehari-hari. Banyak sekali peserta didik yang merasa kesulitan dalam mempelajari kimia dikarenakan materi kimia pada umumnya bersifat abstrak, berkaitan tentang reaksi dan struktur zat serta mengandung konsep-konsep yang komplek (Sirhan, 2007). Seringkali pelajaran kimia disampaikan dengan ceramah dan berpusat terhadap guru, sehingga membuat para peserta didik merasa bosan dengan pelajaran ini dan cenderung hanya mengikuti saja. Kebanyakan siswa mengalami kesulitan dalam mengingat serta memahami pelajaran yang telah diberikan dengan pola pembelajaran yang berpusat pada guru.

Salah satu materi dalam pembelajaran kimia adalah Sistem Periodik Unsur (SPU). Materi tersebut menitik beratkan terhadap kemampuan memori siswa untuk menghafalkan sejumlah unsur-unsur yang ada di dalam SPU. Materi ini juga dapat membuat penerimaan informasi yang kurang efektif terhadap memori jangka panjang siswa, sehingga pemahaman tentang materi tersebut mudah hilang atau mudah dilupakan. Lupa terjadi karena memori jangka pendek tidak pernah ditransfer ke memori jangka panjang atau karena kehilangan kemampuan untuk mengingat informasi yang ada di dalam memori jangka panjang (Nur, 2004). Berdasarkan penelitian Fadilah tahun 2003 permasalahan dapat diidentifikasi sebagai berikut: (1) siswa kesulitan memahami materi kimia khususnya materi SPU, (2) kondisi siswa yang kurang aktif dalam mengikuti pelajaran kimia, (3) pemilihan model dan media pembelajaran yang kurang bervariasi, (4) proses pembelajaran yang berlangsung cenderung didominasi oleh guru (Pembelajaran Teacher Centered Learning) sehingga siswa hanya bertindak sebagai agen pembelajar yang pasif (Fadilah, 2013).

Kesulitan dalam mengatasi materi tersebut maka perlu dibuat inovasi dalam proses belajar dan mengajar. Salah satu cara yang dapat dilakukan dalam mengatasi fakta tersebut perlu menggunakan media yang sesuai dengan kondisi keadaan siswa. Untuk mewujudkan harapan tersebut maka harus memilih media yang sesuai untuk digunakan. Media adalah segala alat fisik yang dapat menyajikan pesan serta merangsang siswa untuk belajar. Media atau alat bantu disadari oleh banyak praktisi pendidikan sangat membantu aktivitas pembelajaran dan mambantu meningkatkan prestasi belajar siswa (Sadiman, 2010). Media Permainan merupakan salah satu cara untuk menciptakan suasana "bermain sambil belajar". Permainan dapat memotivasi siswa untuk belajar. Belajar dapat didefinisikan tambahan pengetahuan atau kemampuan melalui pengalaman, cara yang lebih baik untuk belajar adalah melalui permainan. Permainan Kimia kotak katik merupakan jenis permainan yang melibatkan strategi serta keaktifan dari seluruh peserta. Dalam permaian ini mengharuskan peserta berfikir cepat serta tanggap serta harus tepat dalam mengambil keputusan karena dibatasi oleh waktu dan juga dibutuhkan strategi yang tepat. Dalam permainan ini akan ditampilkan 20 kotak soal dengan susunan $4 \times 5$ baris. Perolehan kotak atas dasar kemampuan menjawab benar dari isi soal didalamnya, pertanyaan salah akan kembali ditutup dan memungkinkan keuntungan bagi Tim lain merebutnya jika mengatahui jawaban benar.

Dari latar belakang diatas maka perlu dilakukan penelitian dan pengembangan media pembelajaran berbasis permainan Kimia kotak katik ini agar dapat menunjang hasil belajar kimia khususnya materi SPU.

\section{METODE PENELITIAN}

Penelitian yang dilaksanakan adalah pra ekperimen. Penelitian yang mengembangkan permainan Kimia Kotak Katik sebagai media pembelajaran pada materi SPU. Sasaran penelitian ialah 12 siswa kelas $X$ (sepuluh) SMA Muhammadiyah 1 Gresik Rancangan penelitian ini mengacu pada desain penelitian One Group Pretest-Posttest Design, yaitu eksperimen yang dilaksanakan pada satu kelompok saja tanpa kelompok pembanding, dengan skema sebagai berikut:

\section{$\mathbf{O}_{1} \times \mathbf{O}_{2}$}


Keterangan :

$\mathrm{O}_{1}=$ Pretest

$\mathrm{O}_{2}=$ Posttest

$\mathrm{X}=$ Perlakuan

\section{Gambar 1. Rancangan Penelitian One Group Pretest Posttest Design}

Selanjutnya dianalisis hasil kegiatan observasi dan respon siswa. Data pengamatan aktivitas siswa digunakan untuk memberikan gambaran tentang aktivitas siswa selama uji coba berlangsung. Lembar pengamatan aktivitas siswa diisi sesuai dengan aktivitas dominan yang dilakukan menggunakan media permainan Kimia Kotak Katik. Perhitungan menggunakan skala Guttman.

\section{Tabel 1. Skala Guttman}

\begin{tabular}{|c|c|}
\hline Jawaban & Nilai/skor \\
\hline Tidak & 0 \\
\hline Ya & 1 \\
\hline
\end{tabular}

Rumus yang digunakan dalam perhitungan hasil pengamatan adalah :

$$
P(\%)=\frac{\sum \text { skor hasil pengumpulan data }}{\text { skr kriterium }} \times 100 \%
$$

Angket respon siswa digunakan untuk mendukung data hasil pengamatan yang diperoleh dari penilaian siswa selama menggunakan permainan Kimia Kotak Katik mengenai kemenarikan media, kejelasan media dan termotivasinya siswa untuk belajar.

Ketuntasan belajar siswa secara individu dikatakan tuntas dalam belajar apabila skor yang diperoleh $\geq 75$. Sedangkan ketuntasan klasikal dicapai jika $75 \%$ atau lebih siswa memperoleh skor $\geq 75$. Hasil belajar siswa didapatkan melalui nilai dari hasil Pretest Posttest kemudian dianalisis dengan cara:

$$
\text { nilai siswa }=\frac{\sum B}{N} \times 100
$$

Keterangan:

$\sum \mathrm{B}=$ jawaban benar

$\mathrm{N}=$ jumlah soal ketuntasan klasikal $=\frac{\sum \text { jumlah siswa yang tuntas }}{\sum \text { jumlah seluruh siswa }} \times 100 \%$

(Riduwan, 2012)f

\section{HASIL DAN PEMBAHASAN}

Hasil penelitian pengembangan permainan kimia kotak katik materi sistem periodik unsur adalah sebagai berikut:

\subsection{Hasil dan Analisis Data Hasil Uji Kelayakan}

Hasil validasi oleh guru kimia ditunjukkan oleh tabel validasi pada gambar 2 berikut ini

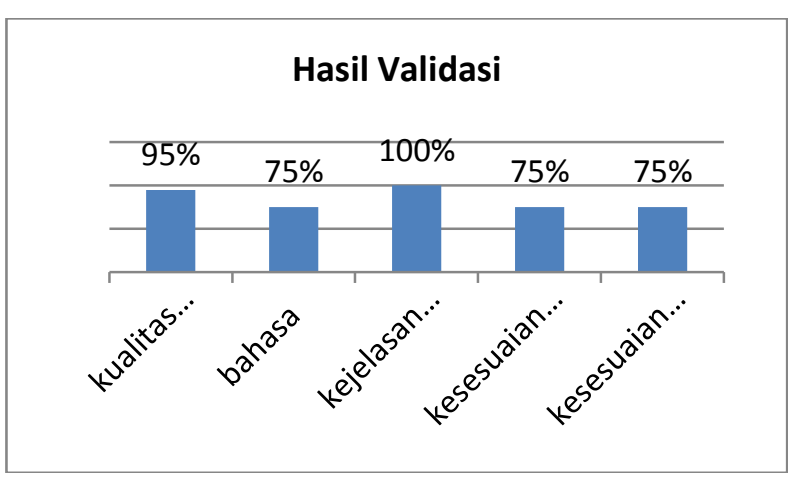

Gambar 2. Hasil Validasi media

Dari hasil validasi guru kimia yang mencakup media pembelajaran sudah sesuai dengan materi pelajaran, hanya saja masih ada beberapa kesalahan soal seperti Ba Barium yang seharusnya merupakan logam namun tertulis dalam soal Ba Barium termasuk non logam. Hukum periodik juga masih belum diajarkan oleh guru sehingga siswa masih belum bisa menjawab soal tersebut meskipun sudah diberikan modul materi sebelum memainkan permainan kimia kotak katik.

Kesesuaian media pembelajaran dengan indikator hasil belajar sudah sesuai namun, Kesesuaian soal dengan indikator hasil belajaran masih belum sesuai karena pada soal nomor 14 terdapat soal yang masih sulit dipahami oleh siswa, sehingga terjadi pemahaman yang salah terhadap soal tersebut.

Kejelasan petunjuk cara bermain dalam media pembelajaran menurut analisis guru kimia sudah jelas. Kesesuaian penggunaan bahasa (kalimat) dengan tingkat kemampuan 
siswa sudah bagus namun terdapat kesalahan penulisan yaitu penggunaan kalimat soal yang cukup membingungkan siswa untuk memahami soal serta jawaban. Hal ini terjadi pada soal nomor 16 dan nomor 10 .

Tampilan / desain media pembelajaran kimia kotak katik sudah bagus dan sudah layak. Kejelasan angka dan huruf pada media pembelajaran kimia kotak katik sudah jelas namun jumlah soal yang diberikan terlalu banyak menurut analisis guru kimia. Keserasian warna pada media pembelajaran kimia kotak katik sudah serasi dan bagus. Kejelasan soal pada media pembelajaran kimia kotak katik masih terdapat beberapa soal yang masih kurang jelas. Kesesuaian ukuran media sudah bagus. Berikut ini tabel skala Likert yang digunakan sebagai rubric analisis penampilan/ desain media (Riduwan, 2012).

Tabel 2. Nilai Skala

\begin{tabular}{|l|c|}
\hline Penilaian & Skala Likert \\
\hline Sangat Tidak baik & 1 \\
\hline Tidak baik & 2 \\
\hline Baik & 3 \\
\hline Sangat baik & 4 \\
\hline
\end{tabular}

Rumus yang digunakan dalam perhitungan hasil validasi dari masing-masing kriteria yaitu kesesuaian isi, penyajian, persyaratan permainan edukatif dan bahasa adalah :

Skor kriterium $=4 \times 10 \times 1=40$

$$
\begin{aligned}
P(\%) & =\frac{\sum \text { skor hasil pengumpulan data }}{\text { skor kriterium }} \times 100 \% \\
P(\%) & =\frac{35}{40} \times 100 \% \\
P(\%) & =87,5 \%
\end{aligned}
$$

Berdasarkan tabel skor interpretasi, kriteria media dikatakan layak jika harga P (dalam \%) $\geq 61 \%$ (Riduwan, 2012). Berdasarkan perhitungan dari hasil validasi guru dan dosen kimia, harga $\mathrm{P}$ pada media yang dikembangkan mencapai 87,5\%. jadi, media yang dikembangkan dapat dikatakan sangat layak.

\subsection{Hasil Analisis Respon Siswa}

Hasil respon siswa adalah sebagai berikut :

Tabel 3. Data Respon Siswa

\begin{tabular}{|c|c|l|l|}
\hline \multirow{2}{*}{$\begin{array}{c}\text { Nomor } \\
\text { pertanyaan }\end{array}$} & \multicolumn{2}{|c|}{$\begin{array}{c}\text { Presentase } \\
\text { (\%) }\end{array}$} & \multirow{2}{*}{ Kategori } \\
\cline { 2 - 3 } & Ya & Tidak & \\
\hline 1. & 83,33 & 16,67 & Layak \\
\hline 2 & 83,33 & 16,67 & Layak \\
\hline 3 & 83,33 & 16,67 & Layak \\
\hline 4. & 83,33 & 16,67 & Layak \\
\hline 5 & 83,33 & 16,67 & Layak \\
\hline 6 & 83,33 & 16,67 & Layak \\
\hline 7 & 83,33 & 16,67 & Layak \\
\hline 8 & 83,33 & 16,67 & Layak \\
\hline 9 & 83,33 & 16,67 & Layak \\
\hline 10. & 83,33 & 16,67 & Layak \\
\hline 11 & 83,33 & 16,67 & Layak \\
\hline 12 & 83,33 & 16,67 & Layak \\
\hline
\end{tabular}

Berdasarkan data tabel 3 tersebut, sebanyak 12 siswa menyatakan tertarik pada permainan kimia kotak katik selama pembelajaran pada materi SPU. Sebanyak 12 siswa juga mengakui bahwa mereka lebih mudah memahami materi pokok SPU dengan menggunakan permainan ini, dengan adanya pengembangan permainan kimia kotak katik dapat memudahkan siswa untuk memahami materi.

Berdasarkan hasil angket respon tersebut dapat diketahui bahwa pengembangan permainan kimia kotak katik di SMA Muhammadiyah 1 Gresik mendapatkan respon yang baik. Siswa merasa senang melakukan kegiatan selama pembelajaran. Selain itu, dengan pengembangan permainan tersebut sangat membantu siswa untuk memahami materi SPU.

\subsection{Analisis Data Aktifitas Siswa}

Berdasarkan data pengamatan aktifitas siswa yang diperoleh, sebanyak 12 siswa memperlihatkan ketertarikan terhadap permainan kimia kotak katik selama pembelajaran pada materi SPU. Siswa juga 
menunjukkan perasaan semangat serta tidak merasa bosan, hal ini dibuktikan saat siswa memilih nomor soal sesuai keinginannya sendiri dan juga penilaian bersifat terbuka sehingga seluruh siswa mengetahui nilainya masing-masing. Siswa juga menunjukkan sikap ketelitian dalam memperhatikan soal yang muncul, dibuktikan dengan pertanyaanpertanyaan yang diajukan siswa karena merasa soal yang muncul masih kurang jelas.

Berdasarkan data hasil pengamatan aktifitas siswa dapat diketahui bahwa siswa merasa senang dan semangat selama pembelajaran materi sistem periodik unsur yang menggunakan media permainan kimia kotak katik.

\subsection{Analisis Ketuntasan Hasil Belajar Siswa}

Untuk mengetahui tingkat pemahaman siswa kelas $X$ pada materi pokok SPU yang sebelumnya siswa telah memperoleh materi tersebut, secara klasikal yaitu dengan pemberian pretest pada awal pembelajaran (sebelum diberi perlakuan permainan kimia kotak katik) dan posttest pada akhir pembelajaran (setelah diberi perlakuan permainan kimia kotak katik). Daftar skor hasil pretest dan posttest disajikan dalam Tabel 6 sebagai berikut:

Tabel 4. Data Hasil Pretest dan Posttes

\begin{tabular}{|c|c|c|c|c|}
\hline No & $\begin{array}{c}\text { Skor } \\
\text { pretest }\end{array}$ & Ket & $\begin{array}{c}\text { Skor } \\
\text { posttest }\end{array}$ & Ket \\
\hline 1 & 45 & $\begin{array}{c}\text { Tidak } \\
\text { tuntas }\end{array}$ & 75 & Tuntas \\
\hline 2 & 25 & $\begin{array}{c}\text { Tidak } \\
\text { tuntas }\end{array}$ & 85 & Tuntas \\
\hline 3 & 30 & $\begin{array}{c}\text { Tidak } \\
\text { tuntas }\end{array}$ & 45 & $\begin{array}{c}\text { Tidak } \\
\text { tuntas }\end{array}$ \\
\hline 4 & 30 & $\begin{array}{c}\text { Tidak } \\
\text { tuntas }\end{array}$ & 40 & $\begin{array}{c}\text { Tidak } \\
\text { tuntas }\end{array}$ \\
\hline 5 & 65 & $\begin{array}{c}\text { Tidak } \\
\text { tuntas }\end{array}$ & 75 & Tuntas \\
\hline 6 & 60 & $\begin{array}{c}\text { Tidak } \\
\text { tuntas }\end{array}$ & 75 & Tuntas \\
\hline 7 & 50 & $\begin{array}{c}\text { Tidak } \\
\text { tuntas }\end{array}$ & 75 & Tuntas \\
\hline 8 & 25 & $\begin{array}{c}\text { Tidak } \\
\text { tuntas }\end{array}$ & 60 & $\begin{array}{c}\text { Tidak } \\
\text { tuntas }\end{array}$ \\
\hline 9 & 20 & $\begin{array}{c}\text { Tidak } \\
\text { tuntas }\end{array}$ & 90 & Tuntas \\
\hline 10 & 35 & $\begin{array}{c}\text { Tidak } \\
\text { tuntas }\end{array}$ & 85 & Tuntas \\
\hline
\end{tabular}

\begin{tabular}{|c|c|c|c|c|}
\hline No & $\begin{array}{c}\text { Skor } \\
\text { pretest }\end{array}$ & Ket & $\begin{array}{c}\text { Skor } \\
\text { posttest }\end{array}$ & Ket \\
\hline 11 & 0 & $\begin{array}{c}\text { Tidak } \\
\text { tuntas }\end{array}$ & 75 & Tuntas \\
\hline 12 & 20 & $\begin{array}{c}\text { Tidak } \\
\text { tuntas }\end{array}$ & 50 & Tuntas \\
\hline
\end{tabular}

Berdasarkan Tabel 5 tersebut, dapat dilihat bahwa pada pretest, jumlah siswa yang tuntas sebanyak 0 orang atau persentase klasikal sebesar $0 \%$ sedangkan siswa yang tidak tuntas sebanyak 12 orang atau sebesar $100 \%$. Persentase yang diperoleh belum memenuhi persentase minimal yaitu sebesar ketuntasan individu $\geq 75$ dan ketuntasan klasikal $\geq 75 \%$ sehingga berdasarkan ketuntasan klasikal masih belum tuntas.

Pada data posttest, ditunjukkan bahwa jumlah siswa yang tuntas sebanyak 8 orang atau persentase klasikal sebesar $66,67 \%$. Sedangkan siswa yang tidak tuntas sebanyak 4 orang atau sebesar 33,33\%. Persentase yang diperoleh belum memenuhi persentase minimal yaitu sebesar ketuntasan individu $\geq$ 75 dan ketuntasan klasikal $\geq 75 \%$ sehingga berdasarkan ketuntasan klasikal masih belum tuntas.

Berdasarkan pembahasan di atas, ketuntasan siswa kelas X SMA Muhammadiyah 1 Gresik setelah mengikuti pembelajaran dengan media permainan kotak katik, hasil belajar siswa meningkat, namun belum mencapai ketuntasan klasikal.

\section{KESIMPULAN}

Berdasarkan hasil analisis dan pembahasan, maka dapat disimpulkan sebagai berikut:

1. Media permainan Kimia kotak katik layak untuk diterapkan untuk materi SPU. Hasil analisis menunjukkan bahwa valliditas $(P)$ mencapai $87,5 \%$ sehingga media sudah sangat layak untuk di uji cobakan secara terbatas.

2. Pelaksanaan penggunaan media Kimia Kotak Katik pada materi SPU pada awalnya masih asing bagi siswa, karena masih dibilang untuk pertama kalinya belajar dengan menggunakan media Software permainan. Meskipun begitu, Berdasarkan hasil observasi serta hasil angket respon 
siswa merasa senang dan tertarik untuk belajar kimia terutama materi SPU dengan menggunakan permainan kimia kotak katik.

3. Berdasarkan hasil analisis ketuntasan siswa kelas X SMA Muhammadiyah 1 Gresik setelah mengikuti pembelajaran dengan media permainan kotak katik, hasil belajar siswa meningkat namun masih belum mencapai ketuntasan klasikal.

\section{DAFTAR PUSTAKA}

BSNP. 2013. Kurikulum 2013. Dalam Kemendikbud.

Fadilah, Q. 2013. Pengaruh Penggunaan Pembelajaran Kooperatif TGT (Teams Game Tournament) Dengan Permainan Word Square dan Crossword Terhadap Prestasi Belajar Ditinjau Dari Kemampuan Memori Siswa Pada Materi Pokok Sistem Periodik Unsur Kelas X SMA Batik 2 Surakarta. Jurnal Pendidikan Kimia (JPK), 2.

Nur, Muhammad. 2004. Teori Pembelajaran Kognitif. Surabaya: UNESA Press.

Peraturan Menteri Pendidikan dan Kebudayaan No. 69 Tahun 2013.

Riduwan. 2012. Skala Pengukuran VariabelVariabel Penelitian. Bandung: Alfabeta.

Sadiman, Arif S. Dkk. 2010. Media Pendidikan: Pengertian, Pengembangan, dan Pemanfaatannya. Jakarta: Rajawali Press.

Sirhan, G. 2007. Learning Difficulties in Chemistry. Journal of Turkish Science Education, 4(2).

Sugiyono. 2013. Metode Penelitian Kuantitatif dan Kualitatif, dan R\&D. Bandung: Alfabeta. 